\title{
Rehabilitation of unilateral peripheral facial paralysis in Guillain-Barré: a case study
}

\author{
Rita Alexandra Mendes Gonçalves ${ }^{1}$ \\ https://orcid.org/0000-0003-1273-8048 \\ Gonçalo José Veríssimo Costa ${ }^{1}$ \\ https://orcid.org/0000-0003-4403-7238 \\ Maria Alexandra Lourenço Afonso ${ }^{2}$ \\ https://orcid.org/0000-0002-5288-9169 \\ Luís Miguel Malaia Amaro Leal Jerónimo' \\ https://orcid.org/0000-0002-3039-4173
}

Centro Hospitalar e Universitário do Algarve E.P.E., Centro de Medicina de Reabilitação do Sul, São Brás de Alportel, Portugal.

Unidade Local de Saúde do Litoral Alentejano, E.P.E., Santiago do Cacém, Portugal.

Conflict of interests: Nonexistent

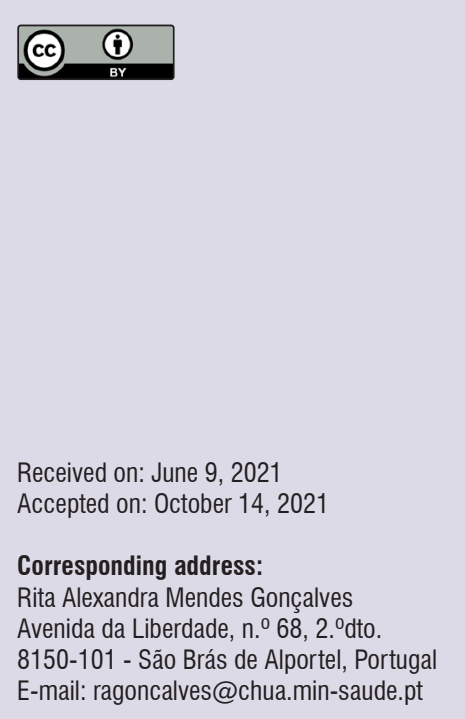

\section{ABSTRACT}

Facial palsies have multiple etiologies, but have in common the negative impact not only on the functions of the stomatognathic system but also on the self-image and emotional expression. This article aimed to describe a case study of unilateral peripheral facial palsy caused by the Guillain-Barré Syndrome.

Hence, it shares assessment and intervention experiences related to this type of change and presents its functional results. It also highlights the important role of the interdisciplinary team (which comprised a physiatrist, physical therapist, speech-language-hearing therapist, occupational therapist, and nurses) to catalyze the patient's evolution and the management of possible complications. Moreover, it is rather important to integrate the patients as members of the rehabilitation team, empowering them and giving them responsibility for the success of the intervention.

Keywords: Guillain-Barré Syndrome; Facial Paralysis, Peripheral; Temporomandibular Joint; Neurological Rehabilitation 


\section{INTRODUCTION}

Facial palsy can be defined as a change in the mimetic muscles caused by a lesion in the facial nerve at any point of its trajectory (from the pons nucleus to the neuromuscular junction) $)^{1,2}$. In peripheral facial palsy (PFP), the muscles in one or both hemifaces are totally or partially involved (depending on its etiology), usually affecting equally the three thirds of the face ${ }^{2}$.

PFP may have numerous etiologies. In this case study, the focus is on the Guillain-Barré Syndrome (GBS), which is an autoimmune change characterized by the acute onset of polyradiculoneuropathies, a quickly progressing weakness in more than one member accompanied by areflexia ${ }^{3-5}$. PFP occurs frequently, although the changes in the mimetic muscles are seldom unilateral ${ }^{3,4,6}$, and its prevalence after full recovery is approximately $6 \% 5$.

The musculoskeletal structure of the face evidently influences the functions of the stomatognathic system - hence, speech, mastication, and swallowing disorders are expected to occur ${ }^{2,3,7,8}$. Compensatory movements, not only to perform these functions but also in the guided exercises, may worsen the structural imbalances $^{2}$ and cause facial pain, particularly in the temporomandibular joint (TMJ).

Facial palsies have an important impact on the person's quality of life, with functional and psychosocial consequences $^{9,10}$. The main difficulties include eyelid ptosis, incomplete eye closure (which increases the risk of eye lesions), lip incompetence (with a resulting impact on speech and swallowing), aesthetic changes, and difficulties expressing emotions (which may lead to social isolation) $)^{9-11}$.

Given the above, this article aimed at presenting a case study on the rehabilitation of a patient with unilateral PFP resulting from GBS and describe the application of a speech-language-hearing and physical therapy intervention approach.

\section{CASE PRESENTATION}

This case study was approved by the Research Ethics Committee of the Centro Hospitalar Universitário do Algarve (Algarve University Hospital Center), Portugal, under process number 029/2021. The patient whose clinical condition is described in this document signed the informed consent form, authorizing his data to be disseminated for scientific purposes.

This case study refers to Mr. N.J., a 44-year-old male patient who was admitted to the Centro de Medicina de
Reabilitação do Sul (Center for Rehabilitation Medicine of the South - CMR-Sul), Portugal, for the rehabilitation of his functional status. It was characterized by severe left PFP (grade $V$ in House and Brackmann classification) $(1985)^{12}$, with partial left eye closure, discrete dysarthria, and no apparent contraction of the muscles dependent on the ophthalmic branch (except for the orbicularis oculi) and the maxillary and mandibular muscles, as a consequence of GBS. He was admitted to the said rehabilitation center approximately 2 months after the appearance of the first symptoms.

In the medical history, Mr. N.J. reported a relevant functional impact of the changes on the mimetic muscles and that recovering from them was his greatest goal in the intervention.

The speech-language-hearing assessment was based on the Chevalier protocol ${ }^{13}$, which assesses the function of each muscle separately. Thus, it quantifies the patient's functional evolution more rigorously and monitors the appearance of contractures and synkinesis ${ }^{14}$.

The face posture assessment at rest revealed the presence of facial asymmetry in the whole left hemiface, with transversal hypofunctioning in all the muscle groups innervated by the seventh cranial nerve, consequently erasing the grooves on the upper third of the face. As for the lower third, the corner of the mouth sharply deviated, and the nasolabial sulcus was erased.

$\mathrm{He}$ was asked to move the muscles, revealing an absence of contraction of the eyebrow corrugator and frontalis muscles. On the other hand, the contraction of the orbicularis oculi was present, enabling partial eye closure.

The facial musculature was assessed with the Chevalier protocol $^{13}$, verifying null or decreased contraction in the following: occipitofrontal (0), eyebrow corrugator (0), procerus/pyramidalis nasi (0), orbicularis oculi (1), palpebral portion of the orbicular oculi (1), levator labii superioris alaeque nasi (0), levator labii superioris (0), zygomaticus minor (0), zygomaticus major (0), buccinator (2), risorius (0), depressor labii inferioris (0), mentalis (0), depressor anguli oris (0), orbicularis oris (0), platysma (2).

The tongue mobility assessment revealed adequate amplitude, speed, tonus, and strength.

Regarding functional intelligibility, verbal articulation was distorted due to left hemiface hypofunctioning. Similar to what has been observed by some authors ${ }^{7,15}$, the consequences were sharper in bilabial and labiodental phonemes. Even though they did not have a 
significant impact on intelligibility, they were notorious and bothered the patient.

The functional swallowing assessment revealed both difficulties holding the food and weak retention of liquids in the oral cavity, especially when drinking from a cup. The liquid would leak forward, which was compensated by placing the cup sideways, on the preserved hemiface, or resorting to the index finger to sustain the left lower lip - similar compensations to those found by Mory et al. ${ }^{8}$. During the preparatory oral phase, there was also an occasional food/liquid escape through the left corner of the mouth, and he tended to chew on the right side - a compensatory mechanism he used to avoid anterior escape ${ }^{7,8}$.

\section{Speech-Language-Hearing Rehabilitation}

Mr. N.J. underwent inpatient speech-languagehearing intervention. The direct intervention took place twice a day, each session lasting 60 minutes, for 7 weeks.

The objectives of the speech-language-hearing face symmetry intervention were to prevent muscle atrophy, potentialize the reinnervation of the affected hemiface ${ }^{14}$, and acquire a more symmetrical facial expression.

During the intervention, the patient remained seated, facing a mirror to help control the facial movements ${ }^{2,16,17}$.

This procedure involved thermal and massage therapy (facial and intraoral massage) on the right hemiface to ease the tension and consequential muscle contractures and associated pain and improve facial symmetry at rest ${ }^{1,2,14,18}$.

The intervention on the left hemiface involved muscle reeducation with various techniques, which were applied on the different muscle groups, then asking him to make the corresponding movements 2,10 . The muscles were stimulated in random order. This principle, along with quick and rhythmic touch stimuli in the direction of the muscle contraction with active vibration, prevented habituation and desensitization ${ }^{19}$.

Cryotherapy was used on the left hemiface, applying ice on the muscle to be stimulated, with quick sliding movements in the direction of the muscle contraction (connection-origin), to encourage muscle contraction ${ }^{1,17}$.

He also made mimetic muscle training and control exercises. He was asked to move specific muscle groups, with easily understood functional commands, thus raising awareness of the movement and avoiding the use of adjacent musculatures to prevent synkinesis and muscle contractures ${ }^{2}$. As he was asked to make movements, the passive support technique was also used, in which the therapist used two fingers to assist the movement, progressively removing the support for the patient to try and maintain the contraction autonomously ${ }^{1,18}$. The exercises were combined with proprioceptive neuromuscular facilitation (PNF), which encourages the use of functional movements and combines auditory feedback with the stretch reflex and resistance principles as movement inducers/ enhancers ${ }^{1,16}$.

The motor points of the affected (left) hemiface were also stimulated with a finger pressure in circular movements, as well as the motor areas of the face, with traction, sliding, and vibration movements ${ }^{7,19}$.

At the end of each intervention session, neuromuscular patches were applied to the muscles of the affected hemiface to stimulate muscle contraction and proprioception. They have been reported in the literature as a supporting method in facial palsy treatment, possibly potentializing the gains $\mathrm{s}^{20,21}$.

The therapeutic recommendations included exercises to be made at the ward, according to the patient's progress ${ }^{7}$. He made the daily exercise rigorously as planned. The instructions highlighted:

- Performing the exercises in front of a mirror, as the visual feedback provides not only an additional sensory cue but also greater control of the facial muscles, preventing the appearance of synkinesis? ${ }^{7}$.

- All exercise should be symmetrical and balanced, and each exercise should be rigorously controlled2;

- Being aware of fatigue and taking breaks not to overload the musculature ${ }^{17}$;

- Frequent relaxation massages on the right hemiface to ease tension and prevent the appearance of muscle contractures due to excessive and compensatory use of that musculature $e^{1,2}$.

- Throughout the hospital stay, eye closure was made during the night, as well as hydration throughout the day to prevent lesions ${ }^{1,2,14}$.

Given the absence of contractions on the left hemiface, the guided exercises were initially limited and were later introduced as his condition progressed ${ }^{11}$. As he managed to make active movements, myofunctional exercises were used to promote isotonic and isometric responses $^{2}$

\section{Complications}

As observed by Miranda et al. (2015) ${ }^{17}$, Mr. N.J. likewise developed compensatory mechanisms to contract the masseter in an effort to potentialize the 
lip stretch movement (smile). This compensation, associated with less efficient mastication ${ }^{22,23}$, made the patient complain of pain when touching the region of the left TMJ at the beginning of the fourth week of intervention, which worsened the speech and mastication functions.

Hence, it was necessary to raise his awareness of this deleterious contraction pattern and then try to inhibit it ${ }^{18}$. Along with the complaints of pain, the TMJ also required specialized follow-up.

\section{Physical Therapy Intervention}

In this regard, a joint effort was made between speech-language-hearing and physical therapy to treat the oral-motor function and better control the pain associated with the compensatory contraction of the masticatory muscles - as it had a negative consequence on the TMJ and affected the progress of the mimetic muscles. Hence, Mr. N.J. began inpatient physical therapy intervention in the fourth week, each session lasting 45 minutes, three times a week, for 3 weeks. It aimed at the painful symptomatology in the left $\mathrm{TMJ}^{24}$, while the speech-language-hearing therapy remained focused on improving the face muscle contractions and raising awareness of and correcting the compensatory movement patterns.

The first postural assessment revealed that the patient had anteriorized the head and shoulders, with a slight increase in the dorsal kyphosis. Mr. N. J. had left TMJ hypomobility (due to protection mechanisms) and felt pain when the left masseter and TMJ were touched. He also reported pain to open and close the mandible. The pain intensity was assessed with the Pain Numerical Scale (PNS) ${ }^{25}$, asking the patient to classify his current pain from 0 "painless" to 10 "the worst imaginable pain"26. Following this classification, the patient graded his pain 6. He did not report pain at rest, and no crepitations were verified in auscultation during mandibular opening and closure, dismissing the possibility of disc-joint changes.

The assessments were made at the beginning of the fourth and end of the sixth week. Both the assessment and intervention were performed with the patient in the supine position. The mandible was in a neutral position and at rest to help relax the face and cervical muscles, as they functionally work against gravity ${ }^{16,24,26}$.

The physical therapy intervention for left TMJ dysfunction aimed to ease the pain, reeducate TMJ mobility, and improve the cervical and scapular girdle posture $26-28$.
The intervention included hand therapy techniques, soft tissue mobilization, and exercises, adapted to the patient's needs ${ }^{26,28}$. He was also instructed how to perform the exercises at the ward; they consisted of postural exercises, following the method suggested by Rocabado ${ }^{29}$ (joint at rest; controlled mandibular opening; TMJ stabilization; stabilized head flexion; cervical retraction; shoulder/scapular girdle retraction) ${ }^{26-28,30}$.

The following exercises were made to gain mobility: TMJ physiological mobility (intraoral technique for opening, closure, protrusion, retrusion, laterotrusion, and mediotrusion); bilateral and unilateral longitudinal-caudal accessory mobilization (extraoral and intraoral technique, respectively), unilateral inward and outward transverse mobilization (extraoral and intraoral technique, respectively) and unilateral posteriorinferior and antero-posterior mobilization (extraoral techniques); and longitudinal-caudal accessory mobilization combined with active mandibular opening and closure $24,26-28$.

The following techniques were used to relax tense musculature and ease the pain: trigger point technique and masseter muscle stretch; and neck musculature stretch combined with the trigger point technique $e^{7,26,27,30}$.

The following techniques were used to optimize the mandibular movement coordination: more selective muscle activation techniques (contraction/relaxation and eccentric control of mandibular opening and closure); and controlled mandibular opening, closure, protrusion, retrusion, and laterality exercises with selfpalpation in both TMJs ${ }^{26-28,30}$.

As previously mentioned, he was given therapeutic recommendations of postural exercises to perform at the ward (six repetitions of each exercise, twice a day), which, according to Rocabado ${ }^{29}$, aimed at joint distraction by eliminating the compression, restoring physiological joint rest, mobilizing the soft tissues, and, whenever possible, improving the condyle-disc-glenoid fossa relationship ${ }^{27,28}$.

\section{RESULTS}

During the hospital stay, Mr. N.J. underwent intensive intervention complemented with indirect therapy. The following performance was verified at hospital discharge:

The assessment of face posture at rest, despite the presence of asymmetry, revealed better defined nasolabial sulcus and a slight increase in tone in relation to the admission; no muscle flaccidity was observed. 
When asked to make the movements, he had difficulties contracting the frontal muscle (0) (similarly to what was verified at admission), whereas the eyebrow corrugator and the procerus hinted a slight contraction with facilitation (1) (it was grade 0 , at first). He had also improved the contraction of the orbicular oculi (which was grade 1 at the beginning of the intervention and 3 , at discharge), enabling him to close the eyes $90-95 \%$.

The peri-orbicular musculature revealed an improved performance in relation to the admission, with slight contractions of the levator labii superioris alaeque nasi (1), zygomaticus (1), risorius (2), and orbicular oris muscles (2). In the initial phase, all these muscle groups were grade 0 , according to the classification of the Chevalier protocol ${ }^{13}$.

Based on what was previously mentioned, this PFP case can be classified as moderately severe (grade IV) in the House and Brackmann classification (1985) ${ }^{12}$.

The gains in muscle strength and amplitude had a favorable impact on the functional performance of speech and of the oral phase of swallowing. In the speech assessment, he still had slight changes due to PFP, although with less interference in the production of bilabial sounds. He had an adequate performance in swallowing, no longer affected by the PFP nor needing compensations.

Concerning the complaints of pain and the decreased TMJ mobility, after 3 weeks of physical therapy without complications or use of analgesics, with concomitant speech-language-hearing therapy, the following performance was verified at discharge:

He gained left TMJ mobility and coordination, with eased pain in physiological mandibular opening and closure movements. The associated pain, which appeared occasionally, was PNS grade $2^{25}$. The pain he felt when touching the left masseter also eased, classified as PNS grade $3^{25}$.

After the discharge, the patient continued with speech-language-hearing follow-up at the hospital near his place of residence.

\section{DISCUSSION}

The mimetic muscle difficulties presented by Mr. N.J. portray the negative impact these disorders have on functioning. Other authors also documented important functional impacts on the stomatognathic functions ${ }^{17}$, particularly swallowing ${ }^{3,8}$ and speech ${ }^{11,15}$.

Concerning swallowing, Mory et al. $(2021)^{8}$ and Tessitore et al. (2009) ${ }^{7}$ reported similar changes and adaptations to those of Mr. N.J. In the oral phase, there was a difficulty with bolus mobilization and anterior escape, due to the hypofunction of the buccinator and orbicularis oris, leading him to use strategies such as preferring the healthy side to chew and to place the cup when drinking liquids. However, the case described by Sun et al. $(2021)^{3}$ also encompassed the pharyngeal phase in the changes resulting from GBS. Sakakibara et al. (2002) ${ }^{6}$ mentioned the possibility of cranial nerves other than the facial ones being affected, particularly the glossopharyngeal and hypoglossal, thus, increasing the severity of dysphagia in this clinical population.

Concerning the impact on speech, various authors mentioned the presence of dysarthria ${ }^{2,3,6,7,18,23}$, resulting from the hypofunctioning of the facial muscles. However, Tessitore et al. (2009) specify the potential impact of facial palsy in these cases, particularly on phonemes $/ \mathrm{f} /, / \mathrm{v} /, / \mathrm{p} /, / \mathrm{b} /$, and $/ \mathrm{m} /$. These phonemes have a strong labial component, and the changes in this structure cause air escape when producing them, resulting in imprecise articulations and, in more severe cases, distortions. Although Mr. N.J. did not have a major speech intelligibility disturbance, the impact of the PFP was evident to both the patient and the interlocutor. Its improvement was one of the objectives of the speech-language-hearing intervention.

Recovering facial symmetry was in itself an important objective of the intervention to Mr. N.J. because, similar to what other authors described ${ }^{9,10,17,18}$, this impairment was perceived as a limitation to his social interaction and emotional expression. Cappeli et al. $(2020)^{10}$ added that the more severe the PFP, the greater the psychosocial impact, negatively affecting the person's self-esteem and interpersonal communication, possibly leading to depression and social isolation.

The biomechanical changes in the stomatognathic functions are also responsible for unbalanced strength, causing complications in the adjacent structures. Various authors ${ }^{17,22,23}$ identified the presence of compensatory contractions in other muscle groups during the mastication or guided exercises, causing TMJ dysfunction. These consequences were also observed during the intervention with Mr. N.J. In this regard, raising his awareness of the masticatory pattern and subsequently reeducating his mastication function and performing hand therapy on the TMJ eased his pain and increased the amplitude of mandibular opening, as verified by Herrera-Valencia et al. (2020) ${ }^{28}$ and Santos et al. (2009) ${ }^{23}$.

The combination of various rehabilitation techniques ${ }^{1,2,14,20,21}$ to provide a wide range of stimuli 
catalyzed the rehabilitation. Even though the symptoms are expected to diminish, this particular case had a fast evolution after the intervention with the physical medicine and rehabilitation team, who performed it adequately, as the intervention was based on controlled exercises, striving always to acquire greater movement control $^{2}$. Perhaps for this reason the facial movements were rehabilitated without the appearance of synkinesis, which could later prolong the treatment, as it is difficult to inhibit.

As pointed out by Robinson and Baiungo (2018) ${ }^{18}$, team interdisciplinarity is rather important in such cases, involving various professionals' fields of expertise and enabling the management of the clinical and functional condition and possible complications. The patient must be integrated as an element of the team ${ }^{11,18}$, sharing responsibility for the success of the intervention as the patient takes an essential role in their own rehabilitation.

In PFP rehabilitation, the stimuli and exercises must be quantified. There are no established "recipes"; the amount of exercise must be defined according to the patients' fatigue, frustration, and tolerance threshold. Hence, the professionals involved in the rehabilitation process must be attentive to different signs and adjust their practice to the patient's needs.

This case illustrates the importance of looking at the person comprehensively during the whole assessment and intervention process. Changes in the biomechanics of a function can impact all the adjacent structures, altering the problem and creating the need to complement the intervention. In this case, different fields of practice observed the same condition and had different, though complementary findings, potentializing the recovery and simultaneously controlling the complications.

\section{CONCLUSION}

The detailed assessment of the case made it possible to quantify the progress, motivating both the patient and the team involved in the rehabilitation. This careful analysis also helped identify and correct compensatory muscle contraction patterns, and, thus, obtain a favorable evolution. This case study demonstrated the impact that interdisciplinarity and communication between professionals can have on the evolution and continuity of the intervention.

\section{ACKNOWLEDGMENTS}

Deepest gratitude is expressed to Mr. N.J., who kindly authorized us to share his clinical case, and to the whole team with whom we had the privilege to work daily.

\section{REFERENCES}

1. Matos C. Paralisia facial periférica: 0 papel da medicina física e de reabilitação. Acta Med Port. 2011;24:907-14.

2. Khalfaoui S, El Abbassi E. Peripheral facial paralysis. J Surg Surg Res [journal on the internet]. 2019 [accessed 2021 Apr 24] 17;5(2):056-60. Available at: https://www.peertechz.com/articles/ JSSR-5-172.php

3. Sun J, Gao Y, Chi L, Cao Q, Ning Z, Nan G. Case report: early-onset Guillain-Barre syndrome mimicking stroke. Front Neurol. 2021;12(February):1-5.

4. Verma R, Chaudhari TS, Giri P. Unilateral facial palsy in Guillain-Barre syndrome (GBS): a rare occurrence. Case Reports [journal on the internet]. 2012 Oct 19 [accessed 2020 Oct 4] ;2012(oct19 1):bcr2012007077. Available at: http://www.ncbi. nlm.nih.gov/pubmed/23087283

5. Huang X, Lan Z, Zhan Y, Hu Z. Case report and literature analysis: Guillain-Barré syndrome with delayed unilateral facial palsy. Front Neurol. 2021;12(March):1-7

6. Sakakibara Y, Mori M, Kuwabara S, Katayama $\mathrm{K}$, Hattori $\mathrm{T}$, Koga $\mathrm{M}$ et al. Unilateral cranial and phrenic nerve involvement in axonal Guillain-Barré syndrome. Muscle and Nerve. 2002;25(2):297-9.

7. Tessitore A, Paschoal JR, Pfeilsticker LN. Avaliação de um protocolo da reabilitação orofacial na paralisia facial periférica: evaluation of an orofacial rehabilitation protocol. Rev. CEFAC. 2009;11(suppl 3):432-40.

8. Mory MR, Tessitore A, Pfeilsticker LN, Couto Junior $E$ de $B$, Paschoal JR. Mastigação, deglutição e suas adaptações na paralisia facial periférica. Rev. CEFAC. 2012;15(2):402-10.

9. Luijmes RE, Pouwels S, Beurskens CHG, Kleiss IJ, Siemann I, Ingels KJAO. Quality of life before and after different treatment modalities in peripheral facial palsy: a systematic review. Laryngoscope. 2017;127(5):1044-51.

10. Cappeli AJ, Nunes HR de C, Gameiro M de OO, Bazan R, Luvizutto GJ. Main prognostic factors 
and physical therapy modalities associated with functional recovery in patients with peripheral facial paralysis. Fisioter e Pesqui. 2020;27(2):180-7.

11. Romao AM, Cabral C, Magni C. Early speech therapy intervention in a patient with facial paralysis after ostomastoiditis. Speech, Lang Hear Sci Educ J. 2015;17(3):966-1003.

12. House JW, Brackmann DE. Facial nerve grading system. Oto- laryngol Head Neck Surg. 1985;93:146-7.

13. Lacôte M, Chevalier AM, Miranda A, Bleton J, Stevenin P. Avaliação da função motora da face nas lesões periféricas e centrais. In: Lacôte $M$, Chevalier AM, Miranda A, Bleton JP, Stevenin P, editors. Avaliação clínica da função muscular. São Paulo, Brasil: Manole; 1987. p. 13-35.

14. Fouquet ML, Lazarini PR. Paralisia facial periférica: atuação fonoaudiológica. In: Filho OL, editor. Novo Tratado de Fonoaudiologia. 3.a. São Paulo, Brasil: Manole; 2013. p. 948-84.

15. Movérare T, Lohmander A, Hultcrantz M, Sjögreen L. Peripheral facial palsy: Speech, communication and oral motor function. Eur Ann Otorhinolaryngol Head Neck Dis [journal on the internet]. 2017 [accessed 2020 Oct 4] ;134(1):27-31. Available at: http://dx.doi.org/10.1016/j.anorl.2015.12.002

16. Adler SS, Beckers D, Buck M. PNF in practice - An illustrated guide. 3rd ed. Stürtz $\mathrm{GmbH}$, Würzburg: Springer; 2008.

17. Miranda V da HM, Scarpel RD, Torres ACM, Agra IMG. Effectiveness of speech therapy in patients with facial paralysis after parotidectomy. Rev. CEFAC. 2015;17(3):984-95.

18. Robinson MW, Baiungo J. Facial rehabilitation: evaluation and treatment strategies for the patient with facial palsy. Otolaryngol Clin North Am [journal on the internet]. 2018 [accessed 2020 Oct 4];51(6):1151-67. Available at: https://doi. org/10.1016/j.otc.2018.07.011

19. Tessitore $A$. O uso da zona motora da língua como facilitadora da deglutição. In: Marchesan I, editor. Tratamento da deglutição. São José dos Campos: Pulso; 2005. p. 101-6.

20. Pathan P. To study the effect of taping technique with conventional therapy in patients with facial palsy: a cross sectional study. Int J Med Heal Res. 2019;5(3):22-4.

21. Sun ZH, Tian YP, Tan YF, Tao D, Li WB, Ding JL et al. Effectiveness of Kinesio taping on peripheral facial paralysis: A protocol for systematic review and meta-analysis. Medicine (Baltimore). 2020;99(46):e23090.

22. Alfaya TA, Tannure PN, Dip EC, Uemoto L, Barcelos R, Gouvêa CVD. Associação entre paralisia facial de Bell e disfunção temporomandibular: manejo clínico. Rev da Fac Odontol UPF [journal on the internet]. 2012 [acsessed 2020 Oct 6] ;17(2):222-7. Available at: http://files.bvs.br/upload/S/14134012/2012/v17n2/a3297.pdf

23. Santos APN, Ganda AM de F, Campos MI da C. Correlação entre paralisia facial e desordem temporomandibular: caso clínico. Rev Odontol da UNESP. 2009;38(2):123-7.

24. Fernández TP, González ÁP. Fisioterapia en el trastorno temporomandibular. 1st ed. Barcelona, Espanha: Elsevier; 2019.

25. Downie WW, Leatham PA, Rhind VM, Wright V, Branco JA, Anderson JA. Studies with pain rating scales. Ann Rheum Dis. 1978;37(4):378-81.

26. Byra J, Kulesa-Mrowiecka M, Pihut M. Physiotherapy in hypomobility of temporomandibular joints. Folia Med Cracov. 2020;60(2):123-34.

27. Butts R, Dunning J, Pavkovich R, Mettille J, Mourad F. Conservative management of temporomandibular dysfunction: a literature review with implications for clinical practice guidelines (Narrative review part 2). J Bodyw Mov Ther [journal on the internet]. 2017 [accessed 2021 Jan 25] ;21(3):541-8. Available at: http://dx.doi.org/10.1016/j.jbmt.2017.05.021

28. Herrera-Valencia A, Ruiz-Muñoz M, Martin-Martin J, Cuesta-Vargas A, González-Sánchez M. Efficacy of manual therapy in temporomandibular joint disorders and its medium-and long-term effects on pain and maximum mouth opening: a systematic review and meta-analysis. J Clin Med. 2020;9(11):3403.

29. Rocabado M, Iglarsh ZA. Musculoskeletal approach to maxillofacial pain. 1st ed. Philadelphia, USA: Lippincott Company; 1990.

30. Şahin D, Kaya Mutlu E, Şakar O, Ateş G, İnan Ş, Taşkıran $\mathrm{H}$. The Effect of the Ischaemic Compression Technique on Pain and Functionality in Temporomandibular Disorders: a randomized clinical trial. J Oral Rehabil. [journal on the internet]. 2021 [accessed 2021 Jan 25];10(1):3-9. Available at: https://onlinelibrary.wiley.com/doi/ 10.1111/joor.13145 